\title{
A Thematic Analysis of Interface Design on Multimedia Teaching Aid of Non-Creative Design Lecturers
}

\author{
Shahrunizam Sulaiman ${ }^{1}$, Norfadilah Kamaruddin 2 \\ ${ }^{1}$ Faculty of Arts and Design, Universiti Teknologi MARA, 32610 Seri Iskandar, Malaysia \\ ${ }^{2}$ Faculty of Arts and Design, Universiti Teknologi MARA, 40450 Shah Alam, Malaysia \\ shahrunizam@uitm.edu.my, norfadilah@uitm.edu.my \\ Tel: +6053742000
}

\begin{abstract}
The digital advancement in tertiary education has created challenges in sustaining an effective teaching and learning process. Significantly, it is important that lecturers design good multimedia teaching aid, to sustain effective teaching and learning content communication. This paper provides an empirical evaluation of how Malaysian tertiary institutions lecturers from non-creative design fields, design an effective multimedia teaching aid to meet these challenges. Although studied samples are limited, outcomes of this paper are an extensively significant reference and guidelines for other area and related multimedia platform locally and internationally.
\end{abstract}

Keywords: interface design principles; interface design; tertiary education level

eISSN: 2398-42870 2020. The Authors. Published for AMER ABRA CE-Bsby e-International Publishing House, Ltd., UK. This is an open access article under the CC BYNC-ND license (http://creativecommons.org/licenses/by-nc-nd/4.0/). Peer-review under responsibility of AMER (Association of Malaysian Environment-Behaviour Researchers), ABRA (Association of Behavioural Researchers on Asians) and cE-Bs (Centre for Environment-Behaviour Studies), Faculty of Architecture, Planning \& Surveying. Universiti Teknologi MARA, Malaysia.

DOl:https://doi.org/10.21834/ebpj.v5iSl3.2562

\subsection{Introduction}

The rapid development of Information Communication Technology (ICT) in recent years has transformed the tertiary education environment. The delivery of teaching and learning content was revolutionized with the convenience of interactive multimedia (Ejaz, Ali, Ejaz, \& Siddiqui, 2019). With this, the lecturers have become the designer in developing an interactive multimedia teaching aid. In any creative design courses, lecturers were equipped with the knowledge in creative design principles foundation. Significantly, they should have no difficulty in preparing a multimedia teaching aid with practical interface design (Lupton \& Philips, 2015; Novoa, M., 2018). Therefore, in ensuring effective teaching and learning engagement, it is significant to investigate how lecturers from noncreative design courses such as science and technical fields design an effective multimedia teaching aid. This is in regards to the importance of promoting well-established multimedia teaching aid together with the learning environment as addressed by researchers (Fang \& Lu, 2015; Ashe, Eardley, \& Fletcher, 2018).

With increased arguments towards tertiary students' engagement, researchers further asserted that there is lack of focus towards interface design principles contributing towards active learning engagement among tertiary students' (Mulqueeny et al., 2015; S. H. Lee \& Song, 2019). With this research problem identified, this research is carried out to identify how do lecturers from non-creative design field apply the valid principle and elements of the interface in their multimedia teaching aid? This research aims to answer the

eISSN: 2398-4287@ 2020. The Authors. Published for AMER ABRA cE-Bsby e-International Publishing House, Ltd., UK. This is an open access article under the CC BYNC-ND license (http://creativecommons.org/licenses/by-nc-nd/4.0). Peer-review under responsibility of AMER (Association of Malaysian Environment-Behaviour Researchers), ABRA (Association of Behavioural Researchers on Asians) and cE-Bs (Centre for Environment-Behaviour Studies), Faculty of Architecture, Planning \& Surveying, Universiti Teknologi MARA, Malaysia.

DOl:https://doi.org/10.21834/ebpj.v5iSI3.2562 
research question how do the principles and aspects of interface design applied towards the multimedia teaching aid supports the delivery of teaching content?

\subsection{Literature Review}

The rapid digital transformation required that it was vital to further provide incomparable learning experience through the active learning engagement (Omar, Dawson, \& Davis, 2019) among the digital native's generation, which was equipped with media and technology advancement (Ejaz et al., 2019). This is significant to its capability in elevating the teaching and learning process, bridging students' knowledge and learning objectives through students learning engagement, which further increased students' creativity (Gorra \& Bhati, 2016; Ejaz et al., 2019). Also towards this, researchers suggested that teaching and learning contents on an interface design of a multimedia teaching aid required specific guidelines according to its design principles (Wu \& Li, 2019).

The interface design was established as a product's 'front-end' through visual communication theory, which facilitated the 'effective teaching and learning process' elements (Ang \& Mohamad, 2014; Ejaz et al., 2019). However, despite the growing number of research in regards to the fundamental guiding principles of effective multimedia design suggested by some researchers, Punchoojit \& Hongwarittorrn (2017) raised the arguments where some existing multimedia interface design are not equally effective. It was also further asserted that there was this lack of understanding of the students' learning barriers in developing the multimedia interface (Erhel \& Jamet, 2019). In regards to this, it is vital to acquire a deeper understanding towards a well-functioned interface design that accommodates good multimedia teaching and learning content for students (T. D. Lee \& Gail Jones, 2017; Wu \& Li, 2019) to meet the challenges in the learning curve (De Marsico \& Fogli, 2017; Ben-Haim, Cohen, \& Tabach, 2019).

\subsection{Methodology}

This study employed a qualitative research design as this approach allowed researchers to interpret a phenomenon based on human experience in its natural settings, as explained by Howitt (2019)(Marshall \& Rossman, 2011). Through the snowball method, twelve respondents which consist of lecturers from the faculty of medical health sciences, engineering, and information technology of public and private tertiary institution from Peninsular Malaysia were identified. Data were collected through a semi-structured interview, which consists of pre-determined open-ended questions, guided by a framework on the lecturers understanding in applying the valid principles and elements of interface design when designing their multimedia teaching aids. The data collected were transcribed and analyzed thematically using both deductive and inductive analysis, using content analysis method and word-based analysis (Mohd Tobi, 2016; Howitt, 2019). This method is useful to identify patterns of ideas in the body of text and is capable of establishing a set of categories, which can be calculated of the occurrences that fall into each theme. In this research, the thematic ideas were based on the principle characteristic guidelines established by in earlier research (Kamaruddin \& Sulaiman, 2016; Sulaiman, 2019)

\subsection{Results}

Based on data collected from the interviews, the thematic analysis was carried out against a set of guiding principles and elements characteristics of interface design for an effective multimedia teaching aid established by scholars (Kamaruddin \& Sulaiman, 2016; Sulaiman, 2019)from earlier research. The content analysis and word-based analysis approach were carried out towards the transcribed interview data. The usage of interface design elements against the principle characteristic guidelines was identified in this study through the pattern of ideas and frequency level of word occurrences identified.

\subsection{Usage of Text Element}

The usage of the text element was reported to be profoundly understood among the lecturers. All lecturers explained that consistency towards the type settings and colour applied towards the teaching aid was maintained, and text and image are integrated appropriately. Majority of the lecturers explained similarly as below:

For types of font, styles I will always consistently use the same font face and sizes on all slides and match colours. (Respondent 3)

I use slides master template for a consistent design type. Normally slide master will have their font size for title, content and bullet list. (Respondent 4)

We use colours which is the same... same size... and the same font format. So, it will have a flow from one slide to the other slide. (Respondent 5)

The image and text next to each other. Yes, it is accompanied by a caption or two to three words explanation of the image. (Respondent 1)

The relevance of the image to support key points in the slides. (Respondent 4)

Table 1 below illustrates a summary of the respondents' analysis.

Table 1. Summary of interface design principles applied towards the text element

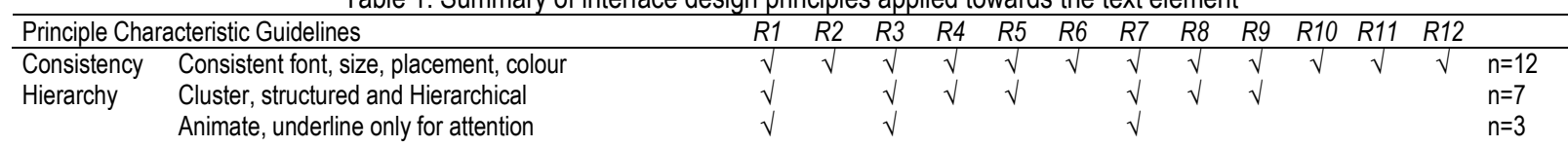




\begin{tabular}{ll} 
Contrast & A short paragraph, Avoid all Capital Letters \\
& San serif copy, No decorative, script, black letter \\
& Contrast against background \\
& Use upper lowercase, limit length line \\
Balance & Paragraphed in a grid column, flush left. \\
Harmony & Limit number of font type \\
& Integrate - text \& diagram appropriately \\
\hline
\end{tabular}

\begin{tabular}{|c|c|c|c|c|c|c|c|c|c|c|c|c|}
\hline$\sqrt{ }$ & & $\sqrt{ }$ & $\sqrt{ }$ & $\sqrt{ }$ & $\sqrt{ }$ & $\sqrt{ }$ & $\sqrt{ }$ & & & & & $n=7$ \\
\hline$\sqrt{ }$ & $\sqrt{ }$ & $\sqrt{ }$ & $\sqrt{ }$ & $\sqrt{ }$ & $\sqrt{ }$ & & $\sqrt{ }$ & & $\sqrt{ }$ & & & $n=8$ \\
\hline & $\sqrt{ }$ & $\sqrt{ }$ & $\sqrt{ }$ & $\sqrt{ }$ & $\sqrt{ }$ & $\sqrt{ }$ & $\sqrt{ }$ & $\sqrt{ }$ & $\sqrt{ }$ & $\sqrt{ }$ & & $n=11$ \\
\hline & $\sqrt{ }$ & $\sqrt{ }$ & & $\sqrt{ }$ & $\sqrt{ }$ & & $\sqrt{ }$ & & $\sqrt{ }$ & $\sqrt{ }$ & & $n=7$ \\
\hline & & $\sqrt{ }$ & & & $\sqrt{ }$ & $\sqrt{ }$ & $\sqrt{ }$ & $\sqrt{ }$ & $\sqrt{ }$ & & & $\mathrm{n}=7$ \\
\hline & & $\sqrt{ }$ & $\sqrt{ }$ & $\sqrt{ }$ & $\sqrt{ }$ & & & & $\sqrt{ }$ & $\sqrt{ }$ & & $n=7$ \\
\hline & $\sqrt{ }$ & $\sqrt{ }$ & $\sqrt{ }$ & $\sqrt{ }$ & $\sqrt{ }$ & $\sqrt{ }$ & $\sqrt{ }$ & $\sqrt{ }$ & $\sqrt{ }$ & $\sqrt{ }$ & $\sqrt{ }$ & $n=12$ \\
\hline
\end{tabular}

\subsection{Usage of Colour Element}

Majority of the lecturers showed a practical usage of contrast in colours, with the majority of the lecturers showed an understanding of the usage of consistency and harmony in colours and the usage of colour. These were explained in some of their response as follow:

For background, I prefer to use a plain background. Normally contra with the colour of the text. (Respondent 2)

For the background colour usually lighter colour example white colour or light purple, and the font will be darker than the background. (Respondent 3)

Use contrast colours and background in order to make the content readable. (Respondent 4)

The colours for the title normally are the same, subtitle is the same colours. (Respondent 1)

These colours should also be consistent with the overall colour scheme of the slides so the image or the fonts does not look out of place. (Respondent 3)

The analysis of the five principles of interface design towards the element of colour is tabulated in Table 2 below.

Table 2. Summary of interface design principles applied towards the element of colour

\begin{tabular}{|c|c|c|c|c|c|c|c|c|c|c|c|c|c|c|}
\hline \multicolumn{2}{|c|}{ Principle Characteristic Guidelines } & $R 1$ & $R 2$ & R3 & $R 4$ & $R 5$ & $R 6$ & $R 7$ & $R 8$ & $R 9$ & $R 10$ & $R 11$ & \multicolumn{2}{|l|}{$R 12$} \\
\hline Consistency & Consistent throughout pages & $\sqrt{ }$ & $\sqrt{ }$ & $\sqrt{ }$ & $\sqrt{ }$ & $\sqrt{ }$ & $\sqrt{ }$ & & $\sqrt{ }$ & & $\sqrt{ }$ & & & $\mathrm{n}=8$ \\
\hline Hierarchy & Groups contents, Hierarchical, functional & $\sqrt{ }$ & & & $\sqrt{ }$ & $\sqrt{ }$ & & & & $\sqrt{ }$ & $\sqrt{ }$ & $\sqrt{ }$ & $\sqrt{ }$ & $n=7$ \\
\hline Contrast & Contrast, foreground and background & $\sqrt{ }$ & $\sqrt{ }$ & $\sqrt{ }$ & $\sqrt{ }$ & $\sqrt{ }$ & $\sqrt{ }$ & $\sqrt{ }$ & $\sqrt{ }$ & $\sqrt{ }$ & $\sqrt{ }$ & $\sqrt{ }$ & & $n=11$ \\
\hline Harmony & Consider Culture, the field Associate & $\sqrt{ }$ & & & $\sqrt{ }$ & $\sqrt{ }$ & $\sqrt{ }$ & $\sqrt{ }$ & & & & & & $n=5$ \\
\hline & Avoid bright colours for long text & $\sqrt{ }$ & & $\sqrt{ }$ & & $\sqrt{ }$ & $\sqrt{ }$ & $\sqrt{ }$ & $\sqrt{ }$ & & $\sqrt{ }$ & & $\sqrt{ }$ & $n=8$ \\
\hline & Aesthetically appealing and pleasing & $\sqrt{ }$ & & & $\sqrt{ }$ & $\sqrt{ }$ & & $\sqrt{ }$ & $\sqrt{ }$ & $\sqrt{ }$ & $\sqrt{ }$ & & $\sqrt{ }$ & $\mathrm{n}=8$ \\
\hline
\end{tabular}

\subsection{Usage of Graphic Element}

Majority of the lecturers only showed an understanding of the principle of contrast and harmony towards applying the elements of the graphic. The principle of consistency and hierarchy, however, is poorly understood by the lecturers. The answers reflected that the respondents have various ways of applying the element of graphic in the interface design of their multimedia teaching aid through the identified principles. Their solutions are in the response below:

I apply them based on the relevance of the image to support key points in the slides. Image as a focal point to attract an audience. (Respondent 4)

Usually if graphic and text, I will change the placement from one slide to the other slide to be different. (Respondent 5)

Each slide is not more than three images in one slide but no specified placement. (Respondent 6)

So the graphic is to support the content of what is being thought during the lesson. (Respondent 1)

I will choose images that have the meaning on the subject matter that I need to explain in the slides. (Respondent 2)

No particular size and positioning where ever I find a space I just insert (giggle...) the picture. (Respondent 10)

I make sure the images are clear and not very small in size. (Respondent 12)

Table 3 below illustrates the analysis of the interface design principles applied towards the element of graphic among the respondents.

Table 3. Summary of interface design principles applied towards the element of graphic

\begin{tabular}{|c|c|c|c|c|c|c|c|c|c|c|c|c|c|c|}
\hline Principle Ch & eristic Guidelines & $R 1$ & $R 2$ & R3 & $R 4$ & R5 & $R 6$ & $R 7$ & $R 8$ & $R 9$ & $R 10$ & $R 11$ & $R 12$ & \\
\hline Consistency & Consistent placement throughout pages & & & $\sqrt{ }$ & $\sqrt{ }$ & & & & $\sqrt{ }$ & $\sqrt{ }$ & & & $\sqrt{ }$ & $n=5$ \\
\hline Hierarchy & Hierarchical to show importance, to emphasize & & & & l & & & & & & $\sqrt{ }$ & & & $n=2$ \\
\hline Contrast & Legibility, Contrast, Avoid picture as background & $\sqrt{ }$ & $\sqrt{ }$ & $\sqrt{ }$ & $\sqrt{ }$ & $\sqrt{ }$ & $\sqrt{ }$ & $\sqrt{ }$ & $\sqrt{ }$ & $\sqrt{ }$ & & $\sqrt{ }$ & & $n=10$ \\
\hline & Clear, Contrast avoid clutter for visibility & $\sqrt{ }$ & $\sqrt{ }$ & $\sqrt{ }$ & $\sqrt{ }$ & & $\sqrt{ }$ & & $\sqrt{ }$ & & & 1 & $\sqrt{ }$ & $n=8$ \\
\hline Harmony & Functional text \& diagram appropriately & $\sqrt{ }$ & $\sqrt{ }$ & $\sqrt{ }$ & & $\sqrt{ }$ & & $\sqrt{ }$ & & $\sqrt{ }$ & & $\sqrt{ }$ & & $\begin{array}{l}n=7 \\
n=0\end{array}$ \\
\hline & Appropriate to content, understandable & $\sqrt{ }$ & $\sqrt{ }$ & $\sqrt{ }$ & & & & $\sqrt{ }$ & & $\sqrt{ }$ & & $\sqrt{ }$ & & $n=6$ \\
\hline
\end{tabular}

\subsection{Usage of Animation Element}

The element of animation is poorly understood by the lecturers, with no understanding of the principle of consistency. The principle of hierarchy, contrast and consistency showed an understanding only among a minority of the lecturers. In applying the element of animation, their opinion is as the responses below:

If moving animation, I rarely use. Because there are times where it will distract the students. (Respondent 1) 
I do not use any animation effect in my slide. The animation will distract the presentation. (Respondent 2)

I keep the background simple, use animations when appropriate. (Respondent 3)

I would say that things that need more clarification maybe at the end of the text so at the end of the sentence we put a nice animated question mark or someone standing with a question mark. So students will catch their eyes on that and perhaps ask more question on that. (Respondent 10)

Table 4 below illustrates the analysis of the interface design principles applied towards the element of animation among the respondents.

Table 4. Summary of interface design principles applied towards the element of animation

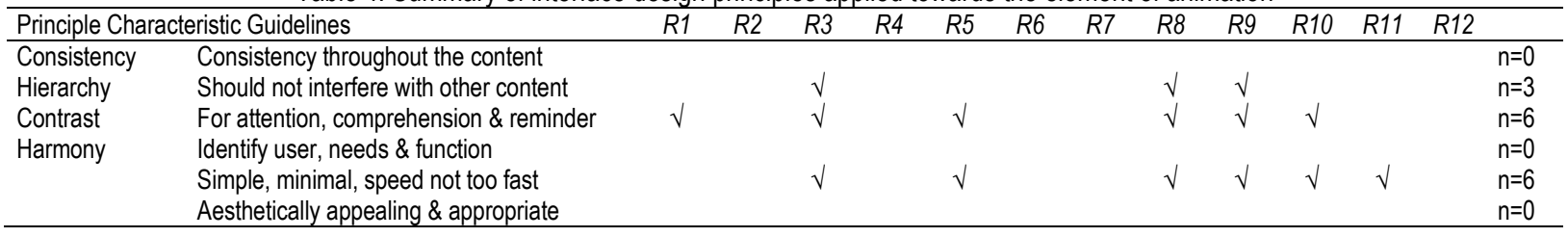

\subsection{Usage of Video Element}

In using the element of video, only a minor average among the lecturers showed an understanding of the principle of contrast and harmony of the usage of footage. The principle of hierarchy showed poor agreement among the lecturers, while the principle of consistency did not show any knowledge of usage among the lecturers. In explaining the usage of video, the lecturers' responds are as below:

The consideration in applying videos are I use contrasting colours to create a dynamic effect. (Respondent 3 )

Yes, I ensure the quality of the video and also the quality of the audio... audio is clear. (Respondent 8)

I keep the visual simple, avoid clutter, noise, and overwhelming towards the slides. (Respondent 3)

I make sure the videos are Simplify and it helps to explain complex problems. (Respondent 4)

The summary of analysis on the interface design principles towards the element of video among respondents is as Table 5 below.

Table 5. Summary of interface design principles applied towards the element of video

\begin{tabular}{|c|c|c|c|c|c|c|c|c|c|c|c|c|c|c|}
\hline \multicolumn{2}{|c|}{ Principle Characteristic Guidelines } & $R 1$ & $R 2$ & $R 3$ & $R 4$ & $R 5$ & $R 6$ & $R 7$ & $R 8$ & $R 9$ & $R 10$ & $R 11$ & $R 12$ & \\
\hline Consistency & Visible placement, minimize usage & & & & & & & & & & & & & $n=0$ \\
\hline Hierarchy & Mostly used for the introduction & & & & & & & & & & & & & $n=0$ \\
\hline & Incorporate user control button & & & & & & & & & & & & & $n=0$ \\
\hline & Breakdown videos by sub-topic & $\sqrt{ }$ & & $\sqrt{ }$ & & & $\sqrt{ }$ & $\sqrt{ }$ & $\sqrt{ }$ & $\sqrt{ }$ & & & & $n=6$ \\
\hline Contrast & Contrast, clarity against a background & & & $\sqrt{ }$ & & $\sqrt{ }$ & & $\sqrt{ }$ & $\sqrt{ }$ & & & $\sqrt{ }$ & & $n=5$ \\
\hline Harmony & $\begin{array}{l}\text { Understandable, simple, accompanying } \\
\text { audio }\end{array}$ & & & $\sqrt{ }$ & $\sqrt{ }$ & & & & & & $\sqrt{ }$ & & & $n=3$ \\
\hline
\end{tabular}

\subsection{Usage of Audio Element}

The final thematic analysis is the element of audio, which consists of the least principal characteristics with only three principle guidelines, which is consistency, balance and harmony. Each of this principle further has only one specific guideline each, making the element of audio has the least principle and characteristic guidelines. The summary of the analysis on the principle of design towards the element of audio is illustrated in Table 6 below.

Table 6. Summary of interface design principles applied towards the element of audio

\begin{tabular}{llcccccccccccc}
\hline Principle Characteristic Guidelines & $R 1$ & $R 2$ & $R 3$ & $R 4$ & $R 5$ & $R 6$ & $R 7$ & $R 8$ & $R 9$ & $R 10$ & $R 11$ & $R 12$ \\
\hline Consistency & Consistency throughout & $\sqrt{ }$ & & $\sqrt{ }$ & $\sqrt{ }$ & $\sqrt{ }$ & & & & $\sqrt{ }$ & $\sqrt{ }$ & $\mathrm{n}=6$ \\
Balance & Suit content 7 atmosphere, synchronize & $\sqrt{ }$ & & $\sqrt{ }$ & $\sqrt{ }$ & $\sqrt{ }$ & & & & & $\mathrm{n}=4$ \\
Harmony & Pleasant, coherent and consistent & $\sqrt{ }$ & & $\sqrt{ }$ & & & & & & & $\mathrm{n}=2$ \\
\hline
\end{tabular}

\subsection{Discussions}

From the analysis above, the principle of consistency towards text was discovered to be the only principle of design that was highly understood by all the lecturers. In the usage of colour, it shows that the contrast in colour usage was highly understood among the lecturers. For the aspect of graphic, it was identified that an average to the low level of understanding towards all the principle characteristic guidelines. Another significant finding from the analysis showed the element of the video is poorly understood. In contrast, the element of audio was moderate and poorly understood among the lecturers when applied against the principle specific guidelines. Surprisingly, the lecturers have a profound understanding of the principle of contrast, which in comparison was against the principle of consistency as established by scholars as to the most important principle of design. The principle of hierarchy and contrast in comparison to the principle of harmony and hierarchy were the second and third important principle of interface design established by scholars. 


\subsection{Conclusion and Recommendations}

The analysis of this research carried out intending to identify how lecturers among the non-creative design field applied the effective principle and elements in designing the multimedia teaching aid. This is in significance to the rapid development of ICT and multimedia in education that raised the need and concerns towards producing a multimedia teaching aid with effective principle and element of interface design. It is essential to sustain an effective teaching and learning process among the millennial. However, there is lack of focus towards the principle and elements of interface design in multimedia teaching aid usage and understanding among lecturers in designing them. The result of this study has shown that the majority of the lecturers highly understood the usage of the text element. The usage of colour and graphic details against the valid design principle was not highly understood among the majority of the lecturer, with poor understanding on the aspect of animation, video and audio usage among the lecturers.

To conclude, the finding from this research has shown that there is a need to readdress the issues towards lecturers understanding in designing their multimedia teaching aid to sustain an effective teaching and learning process. Since the scope of this research was limited, it is also anticipated that future research could investigate how lecturers from other fields of studies such as social sciences and humanities, business and management design the interface of their multimedia teaching aids against the valid principle established by scholars to sustain an effective teaching and learning process. It is also recommended that lecturers from the non-creative design field be provided with the skills in designing a good interface design for their teaching aid through training and workshops in the future.

\section{Acknowledgements}

The research presented in this paper is part of a more substantial study and was supported by the Fundamental Research Grant (FRGS) 2017 under the Ministry of Higher Education, Malaysia.

\section{References}

Ang, T. C., \& Mohamad, M. (2014). A Study of Visual Design in PowerPoint Presentation Slide and Its Relationship with Postgraduate Learner Engagement and Satisfaction. International Proceedings of Economics Development and Research (IPEDR), 78(18), 91-97. https://doi.org/10.7763/IPEDR.

Ashe, D. E., Eardley, W. A., \& Fletcher, B. D. (2018). E-tourism and culture through virtual art galleries: A pilot study of the usability of an interface. 2018 4th International Conference on Information Management, ICIM 2018, (May), 195-200. https://doi.org/10.1109/INFOMAN.2018.8392834

Ben-Haim, E., Cohen, A., \& Tabach, M. (2019). Types of graphic interface design and their role in learning via mathematical applets at the elementary school. Eleventh Congress of the European Society for Research in Mathematics Education.

De Marsico, M., \& Fogli, D. (2017). Guest Editorial: Multimedia for Advanced Human-Computer Interaction. Multimedia Tools and Applications, 76(4), 4849-4854. https://doi.org/10.1007/s11042-016-4024-8

Ejaz, A., Ali, S. A., Ejaz, M. Y., \& Siddiqui, F. A. (2019). Graphic user interface design principles for designing Augmented Reality applications. International Journal of Advanced Computer Science and Applications, 10(2), 209-216. https://doi.org/10.14569/ijacsa.2019.0100228

Erhel, S., \& Jamet, E. (2019). Improving instructions in educational computer games: Exploring the relations between goal specificity, flow experience and learning outcomes. Computers in Human Behavior, 91(May 2018), 106-114. https://doi.org/10.1016/j.chb.2018.09.020

Fang, M. Z., \& Lu, X. (2015). On Multimedia Teaching and Multimedia Software, (1), 292-295.

Gorra, V. C., \& Bhati, S. (2016). Students' perception on use of technology in the classroom at higher education institutions in Philippines Students' perception on use of technology in the classroom at higher education institutions in Philippines Students' perception on Use of Technology. Philippines. Asian Journal of Education and eLearning Asian Journal of Education and e-Learning, 4(03), 92-103. Retrieved from http://ro.uow.edu.au/buspapers/874

Howitt, D. (2019). Introduction to Qualitative Research Methods in Psychology (4th ed.). Harlow: Pearson Education Limited.

Kamaruddin, N. (2012). Interface design in interactive science courseware for the Malaysian Smart School Project. Queensland University of Technology. Retrieved from http://eprints.qut.edu.au/50970

Kamaruddin, N., \& Sulaiman, S. (2016). Understanding Interface Design Principles and Elements Guidelines : A Content Analysis of Established Scholars. In 2nd Art and Design International Conference 2016 (Vol. 2016, pp. 9-11). Shah Alam.

Lee, S. H., \& Song, D. H. (2019). Functional usability analysis of top Korean mobile role-playing games based on user interface design. Indonesian Journal of Electrical Engineering and Computer Science, 13(1), 123-128. https://doi.org/10.11591/ijeecs.v13.i1.pp123-128

Lee, T. D., \& Gail Jones, M. (2017). Elementary Teachers' Selection and Use of Visual Models. Journal of Science Education and Technology, (July 2017), 1-29. https://doi.org/10.1007/s10956-017-9705-1

Lupton, E., \& Philips, J. C. (2015). Graphic Design The new basics (2nd Editio). New York: Princeton Architectural Press.

Marshall, C., \& Rossman, G. B. (2011). Designing Qualitative Research (5th Ed.). California: Sage Publication Ltd.

Mohd Tobi, S. U. (2016). Qualitative Research, Interview Analysis \& Nvivo Exploration. Malaysia: ARAS Publisher. 
Mulqueeny, K., Kostyuk, V., Baker, R. S., \& Ocumpaugh, J. (2015). Incorporating effective e-learning principles to improve student engagement in middle school mathematics. International Journal of STEM Education, 2(1), 15. https://doi.org/10.1186/s40594-015-0028-6

Omar, M., Dawson, M., \& Davis, L. (2019). Developing learning objects for engineering and science fields: using technology to test system usability and interface design. International Journal of Smart Technology and Learning, 1(2), 140. https://doi.org/10.1504/ijsmarttl.2019.10019320

Park, J. Y. (2012). Design process excludes users: the co-creation activities between user and designer. Digital Creativity, 23(1), 79-92. https://doi.org/10.1080/14626268.2012.658814

Punchoojit, L., \& Hongwarittorn, N. (2017). Usability Studies on Mobile User Interface Design Patterns: A Systematic Literature Review. Advances in Human-Computer Interaction, 2017. https://doi.org/10.1155/2017/6787504

Sulaiman, S. (2019). Interface Design Principles, Elements and Characteristics in Multimedia Teaching Aid for Non-Creative Design Field in Malaysian Tertiary Education. Universiti Teknologi Mara, Malaysia.

Vaughan, N. (2014). Student Engagement and Blended Learning: Making the Assessment Connection. Education Sciences, 4(4), $247-264$. https://doi.org/10.3390/educsci4040247

Wu, C. M., \& Li, P. (2019). The visual aesthetics measurement on interface design education. Journal of the Society for Information Display, 27(3), 138-146. https://doi.org/10.1002/jsid.751 